\title{
A new species of Boulengerula Tornier, 1896 (Amphibia: Gymnophiona: Herpelidae) from Kenya and the "rediscovery" of Boulengerula denhardti
}

\author{
MARK WILKINSON ${ }^{1,4}$, PATRICK K. MALONZA ${ }^{2}$, PATRICK CAMPBELL ${ }^{1} \&$ SIMON P. LOADER $^{1,3}$ \\ ${ }^{\prime}$ Life Sciences, The Natural History Museum, London SW7 5BD, UK \\ ${ }^{2}$ Herpetology Section, National Museums of Kenya, Museum Hill Road, Nairobi, Kenya \\ ${ }^{3}$ University of Roehampton, London SW15 4JD, UK \\ ${ }^{4}$ Corresponding author.E-mail: m.wilkinson@nhm.ac.uk
}

\begin{abstract}
A new species of herpelid caecilian, Boulengerula spawlsi sp. nov., is described based on nine specimens from Ngaia (= Ngaya or Ngaja) Forest Reserve, Nyambene Hills, Meru County, Kenya collected between 2007 and 2013. The new species differs from all other Boulengerula in having more anteriorly positioned tentacular apertures and tentacular grooves that are partly or completely covered by the maxillopalatines. Specimens of the new species were previously erroneously reported as a rediscovery of the poorly known congener Boulengerula denhardti Neiden, 1912 together with a biogeographic scenario to explain their disjunct distribution that is not required.
\end{abstract}

Key words: Africa, biogeography, caecilians, morphology, systematics, taxonomy

\section{Introduction}

As currently conceived, the herpelid caecilian genus Boulengerula Tornier, 1896 includes seven species of East African caecilians that are distinctive among African caecilians in having a stapes and lacking secondary annular grooves (Wilkinson et al. 2011). Like their West African sister taxon Herpele Peters, 1880 (Wilkinson et al. 2003; Loader et al. 2007), Boulengerula are heavily ossified caecilians with highly reduced eyes concealed under bone and are considered to be dedicated burrowers (Gower et al. 2004). One poorly known species, B. denhardti Nieden, 1912, had, since Loveridge (1936), been accepted as a junior synonym of Dermophis (now Schistometopum Parker, 1941) gregorii Boulenger, 1895 until it was recognised as a valid species, removed from this synonymy and redescribed by Wilkinson et al. (2004).

In February 2007, Stephen Spawls found a small caecilian in Ngaia (= Ngaya, or Ngaja in local Kimeru) forest, in the Nyambene Hills, Meru County, eastern Kenya. Based on a photograph, Loader et al. (2011: 6) considered that this specimen "most closely resembles $B$. denhardti among known species", referred to it as $B$. cf. denhardti in their figure 1, and commented (p. 13) that more detailed study would be required to determine whether this form is distinct from B. denhardti. Subsequent directed fieldwork by Patrick K. Malonza and Vincent Muchai in May 2008 yielded six additional specimens. These collections formed the basis of the report (Measey et al. 2012), 100 years after its description, of the rediscovery of the poorly known species $B$. denhardti that was previously known only from the holotype specimen from the area of the Tana River in Kenya (Wilkinson et al. 2004).

In 2013 we collected two additional specimens of this Boulengerula from Ngaia forest and have subsequently examined all known specimens from this locality. Here we confirm that they are Boulengerula (lacking secondary annular grooves but possessing stapes) and show that, rather than being $B$. denhardti, this population of caecilians represents an undescribed eighth species of Boulengerula that we here describe. Consequently, contra Measey et al. (2012), B. denhardti has not been rediscoverd in the Nyambene Hills and remains known only from the holotype specimen. 


\section{Material and methods}

Caecilians were obtained by searching under logs and rocks and by digging forest soils with bladed hoes, especially between buttress roots of trees, within and under rotting wood and exclusively during daylight hours. Recently collected specimens were anaesthetized with MS222, fixed in formalin for several days, washed in water and stored in 70\% ethanol or industrial methylated spirits, and deposited in the collections of the National Museums of Kenya, Nairobi (NMK) and the Natural History Museum, London, UK (BMNH). We also examined comparative material from these and from the collections of the Museum of Comparative Zoology, Harvard, USA; the University of Michigan Museum of Zoology, Ann Arbor, USA and the Museum für Naturkunde, Berlin, Germany including holotype or lectotype specimens of all recognized species of Boulengerula.

Skulls and mandibles of three specimens of the new species were visualised with non-destructive highresolution x-ray computed tomography (the results referred to here as CT scans) as described by Gower et al. (2010) but with scan parameters of $150 \mathrm{kV}$ and $200 \mu \mathrm{A}$ and a single frame per projection and with virtual dissection (separation of crania, mandibles and vertebral column) achieved by extracting separately defined regions of interest rather than by rendering them transparent. Comparisons were made with $\mathrm{CT}$ scans of other specimens of Boulengerula reported by Sherratt et al. (2014), and of the holotype of B. denhardti (MW and Emma Sherratt, unpublished).

Total lengths and circumferences were measured to the nearest millimetre $(\mathrm{mm})$ with a ruler, the latter by wrapping a piece of string around the body. Other measurements were made to the nearest $0.1 \mathrm{~mm}$ with dial callipers. Observations and counts of teeth were facilitated by the Nussbaum technique, i.e. using a directed steam of compressed air to temporarily dry and shrink the gingivae (Wilkinson et al. 2013) and through temporary staining of the mouth with Lugol's solution to enhance contrast between teeth and gums. Tooth counts were checked for a subset of specimens from CT scans. For specimens without an everted phallus sex was determined by direct examination of gonads and/or cloacal retractor musculature (see Wilkinson 1990) through midventral incisions in the posterior third of the body. Numbers of vertebrae were determined from radiographs, with numbers of nuchal and tail vertebrae determined for the holotype specimen using the method of Wilkinson (1989). For specimens that were not CT scanned the condition of the tentacular goove was assessed by probing with a fine pin.

Following common usage we refer to an area around the vent that is differentiated in colour or structure from the adjacent skin as the disc. Following Kamei et al. (2009, 2013), Wilkinson \& Kok (2010), Kotharambath et al. (2012a, b) and Agarwal et al. (2013) we refer to the fleshy margins of the upper and lower jaws that form the edges of the mouth as lips and use the following abbreviations for anatomical features and ratios of measurements: $\mathrm{AG}=$ annular groove; $\mathrm{AM}=$ anteromedial limit of the mouth on the upper jaw; $\mathrm{CM}=$ corner of the mouth; $\mathrm{C} 1=$ first collar; $\mathrm{C} 2$ = second collar; $\mathrm{L}=$ lip; $\mathrm{N}=$ naris; $\mathrm{NG1}=$ first nuchal groove; $\mathrm{NG} 2=$ second nuchal groove; $\mathrm{NG} 3=$ third nuchal groove; $\mathrm{OM}=$ outer mandibular (or 'dentary') tooth; $\mathrm{PM}=$ premaxillary-maxillary tooth; $\mathrm{ST}=$ snout tip; $\mathrm{TA}=$ tentacular aperture; $\mathrm{TG}=$ transverse groove on dorsal surface of collar; $\mathrm{TP}=$ tentacular papillus; $\mathrm{TT}=$ terminus tip, the posteriormost point of the body; $\mathrm{VP}=$ vomeropalatine tooth; $\mathrm{L} / \mathrm{W}=$ total length divided by midbody width. Distances involving nuchal grooves refer to a point on the groove directly behind the CM. Following Wilkinson et al. (2013) distances between structures or points of reference are indicated with a dash (e.g. CM-ST). Following Wilkinson et al. (2014) we use first and last to denote the anteriormost and posteriormost units of serial homologues. Additionally, we use front and back (and behind) as synonyms of anterior or posterior respectively. Head width and depth were measured at the back of the head adjacent to NG1. Where helpful, observations were made with the assistance of a dissecting microscope. The abbreviations MW and PKM refer to the authors and field tags.

\section{Boulengerula spawlsi sp. nov.}

urn:Isid:zoobank.org:pub:FCA5F156-422B-4E07-ACF1-189F6BFA873F

(Figs. 1-3, Table 1)

Boulengerula cf. denhardti Nieden, 1912: Loader et al. (2011: 6, figure 1)

Boulengerula denhardti Nieden, 1912: Measey et al. (2012: 187-191, figure 1)

Holotype. NMK A5596/2 (MW 7938), an adult female collected by the authors in Ngaia Forest Reserve, Nyambene Hills, Meru County, Kenya, N 0²2' 47.3" E 38 0' 47.5", 1419 m asl, $23^{\text {rd }}$ January 2013. 
Paratypes ( $\mathrm{n}=8$ ). BMNH 2005.2264 (formerly NMK A5596/1, MW 7937) same data as holotype except N $0^{\circ} 22^{\prime}$ 44.8" E $38^{\circ}$ 0' 45.9", 1406 m asl; BMNH 2005.2265 (formerly NMK A4954/4 / PKM00871), A4954/1 (PKM00847), A4954/2 (PKM00849), A4954/3 (PKM00851), A4954/5 (PKM00873), A4954/6 (PKM00875) collected near the type locality ( $0^{\circ} 23^{\prime} 19.3^{\prime \prime}$ E $38^{\circ} 01^{\prime} 41.6^{\prime \prime}, 1334 \mathrm{~m}$ asl) by PKM and Vincent Muchai, 22-23 May 2008; A/4824 (PKM00622) collected near the type locality ( $0^{\circ} 19.063^{\prime}$ E $38^{\circ} 00.06{ }^{\prime}, 1300 \mathrm{~m}$ asl) by Stephen Spawls $13^{\text {th }}$ February 2007.

Diagnosis. A Boulengerula that differs from all congeners in having the anterior part of the tentacular canal covered by maxillopalatine. It differs further from B. boulengeri Tornier, 1896 and $B$. denhardti in having inner mandibular teeth, from B. changamwensis Loveridge, 1932 and B. fisheri Nussbaum and Hinkel, 1994 in having a mainly darker blue or purple, rather than pink, body colour, and from all other Boulengerula (B. taitanus, Loveridge, 1935, B. niedeni Müller, Measey, Loader \& Malonza, 2005, B. uluguruensis Barbour \& Loveridge, $1928)$ in having more $(>150)$ annuli.

Description of the holotype. Some morphometric and meristic data are in Table 1. Good condition except for some wrinkling and creasing of the skin, a $5 \mathrm{~mm}$ midventral incision c. $90 \mathrm{~mm}$ behind ST, a $7 \mathrm{~mm}$ midventral incision c. $43 \mathrm{~mm}$ anterior of TT.

Body subcylindrical, slightly dorsoventrally flattened, fairly uniform, narrowing noticeably only in the region of the vent and terminal shield; L/W c. 66. In dorsal view, head more U- than V-shaped; sides of head fairly straight and converging substantially from the back of the head to about halfway between TAs and nares, and more strongly anteriorly to a bluntly rounded ST. In lateral view, head wedge-shaped; top of and bottom of head fairly straight and converging strongly up to level of nares and then more curved and strongly converging to narrow rounded tip; upper lip very slightly concave, slightly downturned close to AM; ridge bearing vomeropalatine teeth visible close to CM; lower jaw about one half and one fifth the height of upper jaw at levels of CM and TA respectively. ST much blunter in dorsal than in lateral view. In ventral view, snout projects strongly beyond recessed mouth, anterior margins of upper and lower jaws much more bluntly rounded than ST, sides of upper jaw visible as far back as CM. Eyes not visible. Subcircular TAs very close to lip, slightly elevated, on distinct subcircular TPs, that are just visible dorsally and more so ventrally, much closer to nares than to CMs, below (touching) imaginary lines between nares and CMs, slightly (one TP diameter) posterior to level of AM. Ovate nares small, approximately the same size as TAs, dorsolateral, closer to ST than to level of AM, about as far from bottom as from top of snout and half as far from ST in lateral view, barely visible from below a little more so from above.

Teeth pointed, gently recurved, last few elements of outer mandibular series much smaller. OMs and PMs monocuspid, the former larger; VPs smaller, bicuspid, vomerine series broadly rounded anteromedially, palatine series extending posteriorly much further than premaxillary-maxillary series, cuspidity of paired IM teeth unclear. Distance between vomeropalatine and premaxillary-maxillary series anteriorly much less (approximately half) AM-ST in ventral view; upper teeth series extending posteriorly to about the level of posterior margin of choana. Palate not strongly arched transversely or longitudinally. Choanal apertures subcircular, anterior margins far behind level of TAs, separated from each other by about twice width of single choana. Tongue smooth, somewhat crescent shaped with concave margin posterior, rounded and unattached anteriorly.

Nuchal region scarcely wider than adjacent body and head. Two nuchal collars clearly marked by three nuchal grooves; NG1 and NG2 completely encircling body, NG3 widely incomplete (or at least hard to discern) on the venter. Substantial TG on C2, visible laterally. All grooves in nuchal region bow forward medially on dorsum. NG1 bowing slightly forward ventromedially. A small midventral crease extends from close to the mentum to just past the ventral TG on C1. AGs mostly incomplete dorsally except first 12 and the first 14 of the last 19, complete or narrowly incomplete ventrally; last seven or eight annuli shorter than the others. Last three AGs increasingly difficult to discern, interrupted ventrally by the vent and disc; last approximately level with vent. Body ends in a short terminal shield approximately twice the length of the last annulus (viewed laterally), a little shorter than (3/4 the length of) midbody annuli. Distinct terminal keel on dorsal surface of terminal shield. Body terminus bluntly rounded in dorsal view, narrowing only in the vent region. Rounded in lateral view, ventral surface somewhat flattened. Vent circular, towards the back of an eliptical disc that is longer than wide $(1.8 \times 1.3 \mathrm{~mm})$, perhaps five main denticulations anterior and four posterior, but poorly indicated and with irregular subdivisions, the interdenticular creases reaching to margins of disc and thus longer anteriorly; no papillae. Three vertebrae in the nuchal region, no post-cloacal vertebrae. 


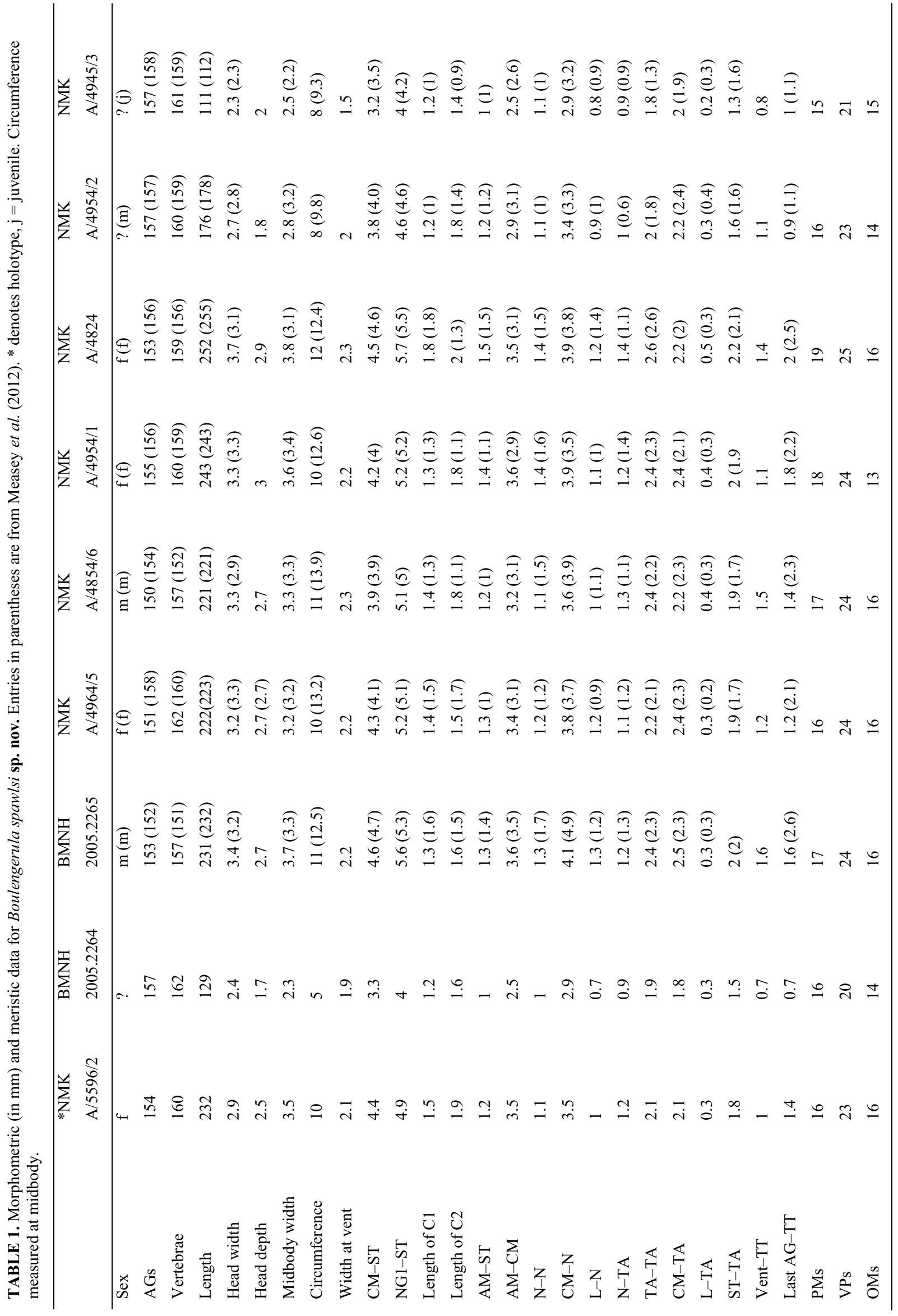




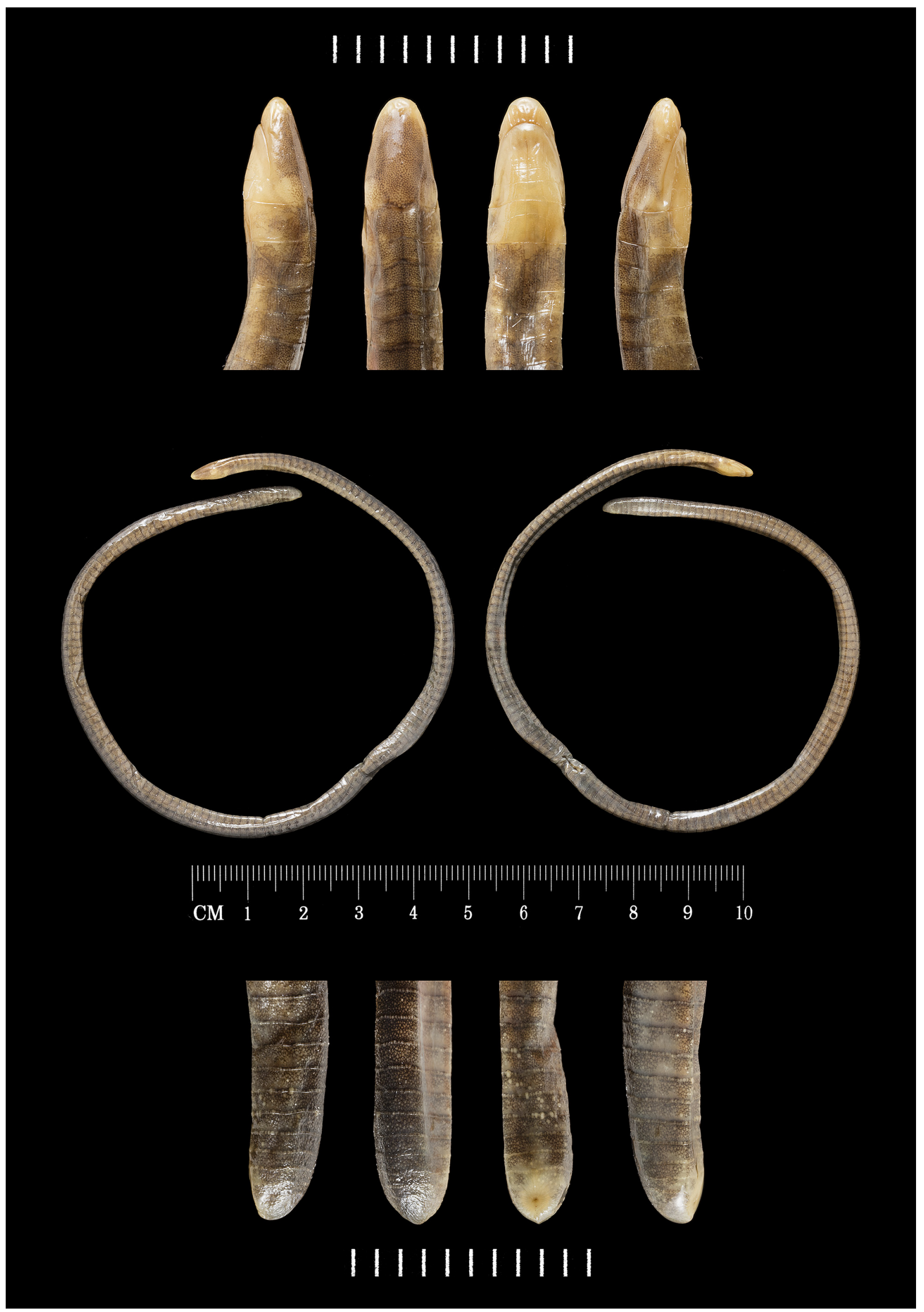

FIGURE 1. NMK A/5596/2, holotype of Boulengerula spawlsi sp. nov. Scale bars in mm. Photo by Harry Taylor (Natural History Museum, London). 
In preservative a slightly bluish olive grey, darker and more blue narrow (2.7 $\mathrm{mm}$ wide) dorsal band not extending laterally onto bulges produced by the underlying superficial external oblique trunk muscle, especially dark along AGs and, anteriorly along dorsal midline. Somewhat paler ventrally, with some much paler patches on flanks especially near the head and terminus. AGs marked by a broad dark band with a medial row of whitish glands visible with magnification. Tip of snout dorsally and entire ventral surface of head pale and unpigmented as far posterior as NG2. TPs encircled by slightly darker narrow ring. Ventral surface of terminal area pale, disk cream.

In life (Fig. 2A-B the holotype was a slightly purplish blue dorsally, slightly paler on the flanks and below with a pinkish head and throat and a pale snout tip. AGs were whitish with this pale colour extending slightly laterally and ventrally on the last few annuli and also surrounding the slightly darker disc.

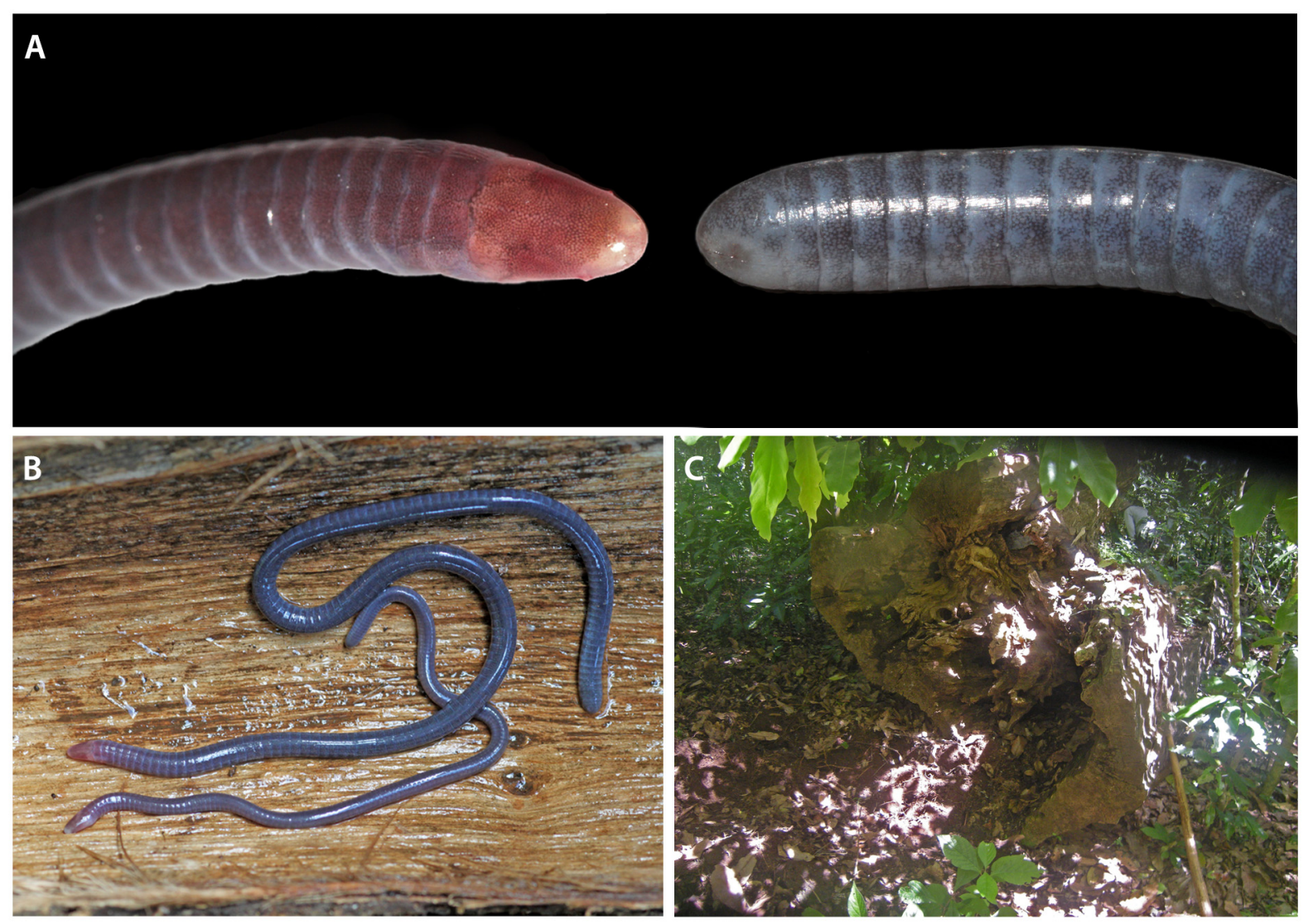

FIGURE 2. Boulengerula spawlsi sp. nov. (A) head and terminus and (B) whole body (with the smaller paratype BMNH 2005.2264) of holotype in life. (C) Habitat at type locality.

Variation and additional information from paratypes. Variation in some meristics and morphometrics is summarised in Table 1. The paratypes agree in most aspects with the holotype. All have a pair of inner mandibular teeth. The most conspicuous variation is in the extent of the pale colour on the throat region which extends further posteriorly onto the collars in some specimens. Most paratypes are a little more dehydrated than the holotype, resulting in some shrinkage and the artefactual appearance (in X-radiographs) of vertebrae behind the level of the vent in some, as has been reported in other species (Nussbaum 1988). One paratype (NMK A4824) has the jaws broken, facilitating determination that the IMs are bicuspid.

CT scans of BMNH 2005.2264 (Fig. 3) and two other paratypes (NMK A4954/5 and A4954/6, data not shown) reveal details of the osteology of the new species. The general composition, shape and arrangement of bones is as in other Boulengerula (De Villiers 1938; Taylor 1969, MW pers. obs.) with the exception, seemingly correlated with the relatively anterior placement of the TA, that the maxillopalatine forms a complete or partial bony covering of the anterior part of the tentacular groove. Other notable features are (1) comparatively weak diastemata between the vomerine and palatine teeth series on each side, (2) PM series that are substantially shorter than (do not extend as far back as) the VP series, (3) a pair of inner mandibular teeth, (4) no exposure of the mesethmoid dorsally, (5) separate (paired, left and right) foramina in the sphenethmoid for the passage of the dorsal roots of the olfactory 
nerve, and (6) imperforate stapes. Three of these $(1,5$ and 6$)$ are additional substantial differences between the three scanned specimens of the new species and the holotype of $B$. denhardti (MW pers. obs.). In all cases, tooth counts made directly from specimens agreed very closely with those made from CT scans (data not shown).

Remarks. The holotype was dug from soil in a hollowed out base of the trunk of a large fallen tree (Fig. 2C) and NMK A5596/1 was collected in the soil beneath a rotting log, these two specimens collected in approximately 12 person hours of digging. NMK A4824 was found under a stone. Large decomposing logs are not very abundant in the forest and not all of them harbour caecilians. The forest is used by the local community and log collecting for firewood may negatively impact the extent of suitable microhabitat for Boulengerula spawlsi. This species does not appear to be as abundant (or at least not as readily found) as some of its congeners. Some other Kenyan Boulengerula, for example B. taitanus and B. niedeni, are more readily found in farmland than in forest (Malonza \& Measey, 2005; Malonza et al., 2010) but whether B. spawlsi occurs outside of forest remains to be determined. The presence of $B$. spawlsi in a protected areas implies some protection for the species, but the extent of its distribution in the forests of the Nyambene Hills (e.g. in Igembe, and Kageta forest blocks that are at higher elevations than Ngaya) and in farmlands outside the forest needs to be better understood to usefully inform its conservation status.

Etymology. The species is named in honour of Stephen Spawls in recognition of his substantial contributions to African herpetology, including his discovery of this species of caecilian.

Suggested English name. Spawls' boolee.

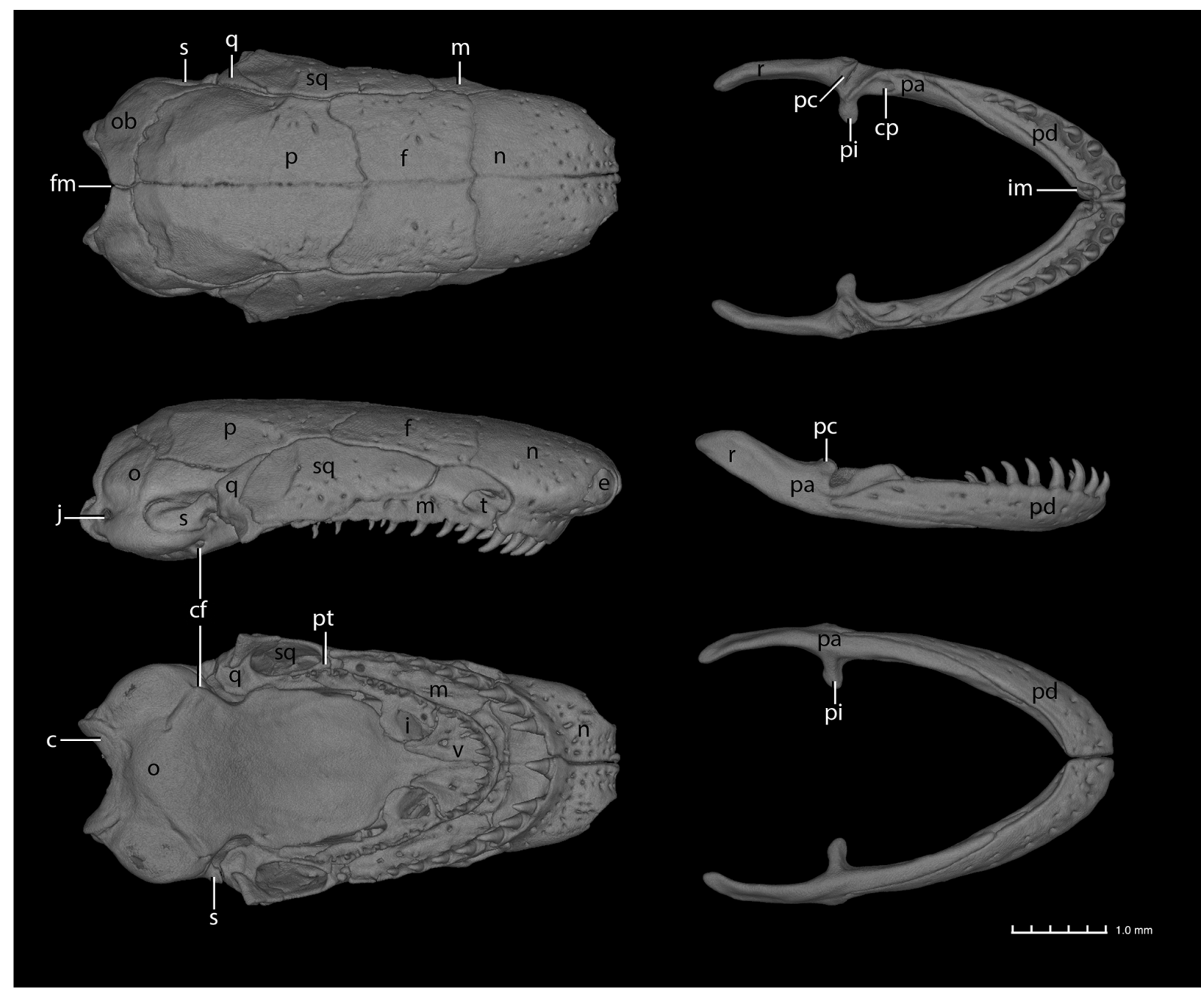

FIGURE 3. CT scan of skull BMNH 2005.2265 Boulengerula spawlsi sp. nov. Scale bars in mm. Upper and lower jaws on left and right respectively, in dorsal (top), right lateral (middle) and ventral (bottom) views. cf = carotid foramen; $\mathrm{cp}=\mathrm{canalis}$ primordialis; $\mathrm{e}=$ external naris; $\mathrm{f}=$ frontal; $\mathrm{fm}=$ foramen magnum; $\mathrm{i}=$ internal nostril (choana); im $=$ inner mandibular tooth series; $\mathrm{j}=$ jugular foramen; $\mathrm{m}=$ maxillopalatine; $\mathrm{n}=$ nasopremaxilla; $\mathrm{o}=\mathrm{os}$ basale; $\mathrm{c}=$ occipital condyle; $\mathrm{p}=\mathrm{parietal} ; \mathrm{pa}=$ pseudoarticular; $\mathrm{pc}=$ processus condyloides; $\mathrm{pd}=$ pseudodentary; $\mathrm{pi}=$ processus internus; $\mathrm{pt}=$ pterygoid; $\mathrm{q}=\mathrm{quadtrate} ; \mathrm{r}=$ retroarticular process of the pseudoangular; $\mathrm{s}=$ stapes; $\mathrm{sq}=$ squamosal; $\mathrm{t}=$ tentacular aperture; $\mathrm{v}=$ vomer. 


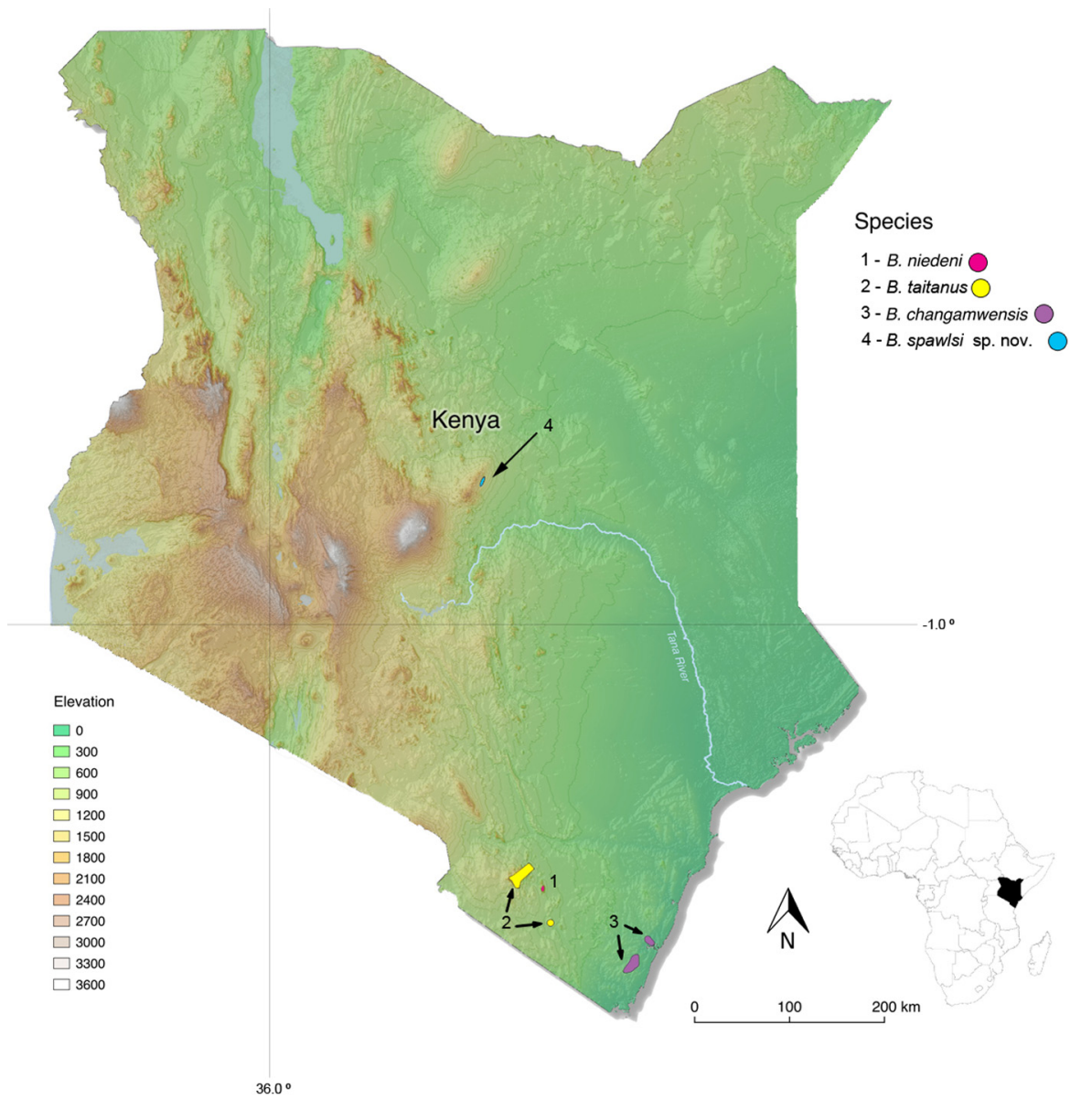

FIGURE 4. Map showing distribution of Boulengerula species in Kenya. Boulengerula denhardti is known only from the imprecise locality of the Tana River. Arrow highlights the distribution of B. spawlsi sp. nov. Distributions of $B$. changamwensis, B. niedeni and B. taitanus based on data from the IUCN Red List (http://www.iucnredlist.org/).

\section{Discussion}

From a photograph, Loader et al. (2011: 12-13) identified the caecilian discovered by Stephen Spawls in the Nyambene Hills as "a Boulengerula, based on body and head shape, lack of externally visible eyes, unsegmented terminal shield and lack of secondary annular grooves. They noted that "If confirmed, this would be the most northerly record for the genus, and the only one north of the equator. The individual has about 153 annuli (more than are known for any species except the 161 of $B$. denhardti and 186 of B. fischeri), and its purplish colour (darker dorsally) with whitish annular grooves readily distinguishes it from B. changamwensis, B. fischeri, $B$. niedeni, B. taitanus and B. uluguruensis. More detailed study will be required to determine whether this form is distinct also from B. denhardti." For the Nyambene Hills Boulengerula, Measey et al. (2012: 187) subsequently reported that "Morphological examination of seven specimens suggests that they are closer to the type of $B$. denhardti than to any other member of the genus." In contrast, we find the Nyambene Boulengerula to be most similar to B. denhardti among other Boulengerula only in the numbers of annuli.

After a discussion of the small differences between the Nyambene Hills Boulengerula and the holotype of $B$. denhardti in the numbers of annuli, Measey et al. (2012: 188) concluded that "On balance, as the specimens we collected do not fall in the diagnosis of any other described Boulengerula, and as their morphology does not clearly contradict the diagnosis given by Wilkinson et al. (2004), we tentatively identify these specimens as $B$. denhardti." However, this identification is plainly contradicted by the presence of inner mandibular teeth in the Nyambene Hills Boulenegerula (as noted by Measey et al. 2012), the absence of which was used by Wilkinson et al. (2004) in their diagnosis of $B$. denhardti and in their key to the species of Boulengerula. Presence or absence of inner mandibular teeth has been used previously as a diagnostic character for species of Boulengerula (e.g. Nussbaum 
and Hinkel, 1986) and Taylor (1968) used this as a genus level character for a currently unaccepted partitioning of Boulengerula, so this difference alone is more than sufficient to rule out an assignment of the Nyambene Hills Boulengerula to $B$. denhardti. Other substantial differences noted above between the osteology of $B$. denhardti and the Nyambene Hills Boulengerula leave no doubt that they are not conspecific and support our recognition of the latter as a new species. There is also at least one obvious and substantial difference in external morphology between the Boulengerula from the Nyambene Hills and the holotype and only previously reported specimen of $B$. denhardti. Measey et al. (2012) give the distances from the tentacle to the tip of the snout and to the corner of the mouth, with the former much larger $(2.5 \mathrm{~mm})$ than the latter $(1.5 \mathrm{~mm})$ in the holotype of $B$. denhardti but this difference is reversed in the Nyambene Boulengerula, reflecting the latter's substantially more anterior tentacles. Tentacle position is an often used character for differentiating caecilian taxa.

Boulengerula denhardti is known only from the holotype specimen, which has an imprecise locality: the area of the Tana River (Wilkinson et al. 2004). Measey et al. (2102) state that this type locality is widely interpreted as being the Tana River Delta, approximately $420 \mathrm{~km}$ southeast of the Nyambene Hills. Having mistakenly believed they had rediscovered $B$. denhardti, Measey et al. (2012) proposed that the distributional gap between the Nyambene Hills and the Tana River Delta could be explained by the former falling within the catchment of the Tana River and by the implication that these localities may have been connected by forested riverine corridors along which caecilians could have dispersed. Our finding that the specimens from Nyamabene Hills are not conspecific with $B$. denhardti but instead represent a new species, obviates any need for the Measey et al. (2012) biogeographic scenario.

There are a number of differences between our morphometric and meristic data and those reported by Measey et al. (2012). Most of these differences are small and attributable to stochastic measurement error but some differences are more substantial (e.g. measurements of the circumference) and seem more likely to reflect differences between investigators in how these data were taken. We have repeated counts of vertebrae and annuli and are confident in our meristic data. We consider the report (Measey et al. 2012) of some specimens having fewer vertebrae than primary annuli to be indicative of inaccurate counts given that the reverse is an almost universal pattern in those caecilian species with primary annuli that can be identified as such. We note that the final vertebrae may be small and difficult to count.

\section{Acknowledgments}

We thank Mark-Oliver Rödel, Rainer Günther and Detlev Langer (Berlin), José Rosado (Harvard) and Ron Nussbaum and Greg Schneider (Michigan) for facilitating loans of or other access to specimens in their care. We are grateful to Emma Sherratt for producing comparative CT scans. We thank Gabriela B. Bittencourt for substantial help in preparing figures and David Blackburn, David Gower and an anonymous reviewer for comments that improved the manuscript. PKM's fieldwork of 2008 was supported by the Kenya Wildlife Service. Our fieldwork in 2013 was supported in part by funding from the Natural History Museum, London.

\section{References}

Agarwal, I., Wilkinson, M., Mohapatra, P.P., Dutta, S.K., Giri, V. \& Gower, D.J. (2013) The first teresomatan caecilian (Amphibia: Gymnophiona) from the Eastern Ghats of India - a new species of Gegeneophis Peters, 1880. Zootaxa, 3693 (4), 534-546. https://doi.org/10.11646/zootaxa.3693.4.7

De Villiers, C.G.S. (1938) A comparison of some cranial features of the East African gymnophiones Boulengerula boulengeri Tornier and Scolecomorphus uluguruensis Boulenger. Anatomische Anzeiger, 86, 1-26.

Gower, D.J., Loader, S.P., Moncrieff, C.B. \& Wilkinson, M. (2004) Niche separation and comparative abundance of Boulengerula boulengeri and Scolecomorphus vittatus (Amphibia: Gymnophiona) in an East Usambara forest, Tanzania. African Journal of Herpetology, 53, 183-190. https://doi.org/10.1080/21564574.2004.9635510

Gower, D.J. \& Wilkinson, M. (2002) Phallus morphology in caecilians (Amphibia, Gymnophiona) and its systematic utility. Bulletin of the Natural History Museum: Zoology, 68, 143-154. https://doi.org/10.1017/s096804700200016x

Gower, D.J., Wilkinson, M., Sherratt, E. \& Kok, P.J. (2010) A new species of Rhinatrema Duméril \& Bibron (Amphibia: 
Gymnophiona: Rhinatrematidae) from Guyana. Zootaxa, 2391, 47-60.

Kamei, R.G., Wilkinson, M., Gower, D.J. \& Biju, S.D. (2009) Three new species of striped Ichthyophis (Amphibia: Gymnophiona: Ichthyophiidae) from the northeast Indian states of Manipur and Nagaland. Zootaxa, 2267 (1), $26-42$. https://doi.org/10.11646/zootaxa.2267.1.2

Kamei, R.G., Gower, D.J., Wilkinson, M. \& Biju, S. (2013) Systematics of the caecilian family Chikilidae (Amphibia: Gymnophiona) with the description of three new species of Chikila from northeast India. Zootaxa, 3666 (4), 401-435. https://doi.org/10.11646/zootaxa.3666.4.1

Kotharambath, R., Wilkinson, M., Oommen, O.V., George, S., Nussbaum, R.A. \& Gower, D.J. (2012a) On the systematics, distribution and conservation status of Ichthyophis longicephalus Pillai, 1986 (Amphibia: Gymnophiona: Ichthyophiidae). Journal of Natural History, 46, 2935-2959. https://doi.org/10.1080/00222933.2012.717972

Kotharambath, R., Gower, D.J., Oommen, O.V. \& Wilkinson, M. (2012b) A third species of Gegeneophis Peters (Amphibia: Gymnophiona: Indotyphlidae) lacking secondary annular grooves. Zootaxa, 3272, 26-34.

Loader, S.P., Pisani, D., Cotton, J.A., Gower, D.J., Day, J.J. \& Wilkinson, M. (2007) Relative timescales reveal multiple origins of parallel disjunct distributions of African caecilian amphibians. Biology Letters, 3, 505-508. https://doi.org/10.1098/rsbl.2007.0266

Loader, S.P., Wilkinson, M., Cotton, J.A., Measey, G.J., Menegon, M., Howell, K.M., Müller, H. \& Gower, D.J. (2011) Molecular phylogenetics of Boulengerula (Amphibia: Gymnophiona: Caeciliidae) and implications for taxonomy, biogeography and conservation. The Herpetological Journal, 21, 5-16.

Loveridge, A. (1936) Scientific results of an expedition to rain forest regions in eastern Africa VII Amphibians. Bulletin of the Museum of Comparative Zoology, Harvard, 79, 369-430.

Malonza, P.K., Lötters, S. \& Measey, G.J. (2010) The montane forest associated amphibian species of the Taita Hills, Kenya. Journal of East African Natural History, 99 (1), 47-63. https://doi.org/10.2982/028.099.0103

Malonza, P.K. \& Measey, G.J. (2005) Life history of an African caecilian: Boulengerula taitanus Loveridge 1935 (Amphibia Gymnophiona Caeciilidae). Tropical Zoology, 18, 49-66. https://doi.org/10.1080/03946975.2005.10531214

Measey, G.J., Muchai, V. \& Spawls, S. (2012) Rediscovery of Boulengerula denhardti Nieden 1912 (Amphibia: Gymnophiona: Caeciliidae) in Meru County, Kenya. African Zoology, 47, 187-191. https://doi.org/10.3377/004.047.0118

Nussbaum, R.A. (1988) On the status of Copeotyphlinus syntremus, Gymnopis oligozona, and Minascaecilia sartoria (Gymnophiona, Caeciliidae): a comedy of errors. Copeia, 1988, 921-928. https://doi.org/10.2307/1445715

Nussbaum, R.A. \& Hinkel, H. (1994) Revision of East African caecilians of the genera Afrocaecilia Taylor and Boulengerula Tornier (Amphibia: Gymnophiona: Caeciliaidae). Copeia, 1994, 750-760. https://doi.org/10.2307/1447192

Sherratt, E., Gower, D.J., Klingenberg, C.P. \& Wilkinson, M. (2014) Evolution of cranial shape in caecilians (Amphibia: Gymnophiona). Evolutionary Biology, 41, 528-5425. https://doi.org/10.1007/s11692-014-9287-2

Taylor, E.H. (1968) The caecilians of the world: a taxonomic review. University of Kansas Press, Lawrence, $848 \mathrm{pp.}$

Taylor, E.H. (1969) Skulls of Gymnophiona and their significance in the taxonomy of the group. University of Kansas Science Bulletin, 48, 585-687.

Wilkinson, M. (1989) On the status of Nectocaecilia fasciata Taylor, with a discussion of the phylogeny of the Typhlonectidae (Amphibia: Gymnophiona). Herpetologica, 45, 23-36.

Wilkinson, M. (1990) The presence of a musculus retractor cloacae in female caecilians (Amphibia: Gymnophiona). Amphibia-Reptilia, 11, 300-304. https://doi.org/10.1163/156853890X00221

Wilkinson, M. \& Kok, P.J.R. (2010) A new species of Microcaecilia (Amphibia: Gymnophiona: Caeciliidae) from Guyana. Zootaxa, 2719, 35-40.

Wilkinson, M., Loader, S.P., Gower, D.J., Sheps, J.A. \& Cohen, B.L. (2003) Phylogenetic relationships of African caecilians (Amphibia: Gymnophiona): insights from mitochondrial rRNA gene sequences. African Journal of Herpetology, 52, 8392. https://doi.org/10.1080/21564574.2003.9635483

Wilkinson, M., Loader, S.P., Müller, H. \& Gower, D.J. (2004) Taxonomic status and phylogenetic relationships of Boulengerula denhardti Nieden, 1912 (Amphibia, Gymnophiona, Caeciliidae). Zoosystematics and Evolution, 80, 41-51. https://doi.org/10.1002/mmnz.20040800104

Wilkinson, M., San Mauro, D., Sherratt, E. \& Gower, D.J. (2011) A nine-family classification of caecilians (Amphibia: Gymnophiona). Zootaxa, 2874, 41-64.

Wilkinson, M., Sherratt, E., Starace, F. \& Gower, D.J. (2013) A new species of skin-feeding caecilian and the first report of reproductive mode in Microcaecilia (Amphibia: Gymnophiona: Siphonopidae). PLoS ONE, 8 (3), e57756. https://doi.org/10.1371/journal.pone.0057756

Wilkinson, M., Presswell, B., Sherratt, E., Papadopolou, A. \& Gower, D.J. (2014) A new species of striped Ichthyophis Fitzinger, 1826 (Amphibia: Gymnophiona: Ichthyophiidae) from Myanmar. Zoootaxa, 3785 (1), $45-58$. https://doi.org/10.11646/zootaxa.3785.1.4 